\title{
Psychoeducational support to post cardiac surgery heart failure patients and their partners: A randomised pilot study
}

\author{
Susanna Ågren, Sören Berg, Rolf Svedjeholm and Anna Strömberg
}

\author{
Linköping University Post Print
}

Tweet

N.B.: When citing this work, cite the original article.

Original Publication:

Susanna Ågren, Sören Berg, Rolf Svedjeholm and Anna Strömberg, Psychoeducational support to post cardiac surgery heart failure patients and their partners: A randomised pilot study, 2015, Intensive \& Critical Care Nursing, (31), 1, 10-18.

http://dx.doi.org/10.1016/i.iccn.2014.04.005

Copyright: Elsevier

http://www.elsevier.com/

Postprint available at: Linköping University Electronic Press

http://urn.kb.se/resolve?urn=urn:nbn:se:liu:diva-109501 
Psychoeducational support to post cardiac surgery heart failure patients and their partners - a randomised pilot study 


\begin{abstract}
Objectives Postoperative heart failure is a serious complication that changes the lives of both the person who is critically ill and family in many ways. The purpose of this study was to evaluate the effects of an intervention in postoperative heart failure patient-partner dyads regarding health, symptoms of depression and perceived control.
\end{abstract}

Research Methodology/Design, Pilot study with a randomised controlled design evaluating psychosocial support and education from an interdisciplinary team.

Setting Patients with postoperative heart failure and their partners.

Main Outcome Measures; SF-36, Beck Depression Inventory, Perceived Control at baseline, 3 and 12 months.

Results A total of 42 patient-partner completed baseline assessment. Partners in the intervention group increased health in the role emotional and mental health dimensions and patients increased health in vitality, social function and mental health dimensions compared with the control group. Patients' perceived control improved significantly in the intervention group over time.

Conclusion Psychoeducational support to post cardiac surgery heart failure dyads improved health in both patients and partners at short term follow-up and improved patients' perceived control at both short and long-term follow-up. Psychoeducational support appears to be a promising intervention but the results need to be confirmed in larger studies. 
Keywords: education, family, heart failure, intervention, postoperative complications, psychosocial support, quality of life 


\section{Introduction}

Postoperative heart failure (PHF) is a serious complication that remains the main cause for early mortality after cardiac surgery. It is associated with increased postoperative morbidity and serious secondary complications such as renal failure. Postoperative heart failure therefore prolongs hospital stay and may influence the benefit of surgery and long-term survival negatively in patients who can be discharged (Holm J, 2010, Vanky et al. , 2007, Vanky et al. , 2006). This complication changes the lives of both the person who is critically ill and of close relations in many ways (Van Horn and Tesh, 2000).

As hospital length of stay in general continue to decrease, patients and families must learn to manage more recovery at home (Micik and Borbasi, 2002). This in turn puts greater responsibility and workload on the patient and relatives. In addition to the problems with the cardiac disease itself, the postoperative course is also burdened with reduced emotional and functional wellbeing. Areas of concern for both the cardiac surgery patient (Tully et al. ,2008) and the family during recovery are anxiety, sadness and depression and worsened health-related quality of life (HRQOL) (McCrone et al. , 2001, Tully et al. , 2009). These emotions can negatively affect the physical and social recovery of the patient and have a negative impact on family functioning (Doering LV, 2005, Knoll SM, 2000, Lopez V, 2007). The findings highlight the need to develop suitable interventions that target improving outcomes regarding mental well-being and health (Tully, Baker, 2008). 
The need of information and support for patients and their families during recovery at home are not always met and the needs of the principal carer (often the patient's spouse/partner) are frequently not addressed (Agren et al. , 2009(Boyd KJ, 2004, Boyd et al. , 2009, Mårtensson J, 2001). (Agren et al. , 2009)When the families and the patients are well informed there is a basis for fruitful communication between them and the healthcare professionals, preparing them if complications occur (Ivarsson B, 2011). Studies have concluded that family interventions in patients with chronic illness have positive effects on outcomes among both patients and their families (Chelsa, 2010, Hartmann et al. , 2010, Martire LM, 2004). Psycho educational intervention has been found to reduce anxiety and depression in patients with HF (Sullivan et al. , 2009), and educational interventions in the intensive care unit reduces anxiety and increases family satisfaction (Chien et al. , 2006). The strategies of psycho-educational intervention include an evaluation of the advantages and disadvantages of different types of behavior and coping styles. Further, it involve sharing of information as well as support from the health care team to obtain positive beliefs and better decision making(Sharif F, 2012). Follow-up visits were seen as an important way of learning what had happened during the period of critical illness (Engstrom et al. , 2008). However, no intervention study to date has focused on patient-partner affected by heart failure complication after thoracic surgery. 
The purpose of the present study was to evaluate the effects of an intervention with psychosocial support and education to post cardiac surgery heart failure dyads regarding health, symptoms of depression and perceived control.

\section{Methods}

We performed a randomised controlled pilot study of postoperative cardiac patients and their partners.

Setting and participants

The University Hospital in Linköping is the sole provider of cardiothoracic surgery in southeastern Sweden, serving a catchment area of approximately 1 million inhabitants. The department is the only unit in the area and it performs approximately 800 cardiac operations annually. The inclusion criteria were to be a dyad consisting of a patient diagnosed with PHF, with a partner living in the same household as the patient, and recently discharged from the hospital (i.e. 2-3 weeks). Exclusion criteria for the dyads were dementia, or other severe psychiatric illnesses, drug abuse, difficulties in understanding or reading the Swedish language, undergoing cardiac surgery including cardiac transplant or participating in other studies. A flow chart illustrating the sample process is shown in figure 1. Patients with an uncomplicated postoperative course leave the ICU the morning after surgery 
for a step down unit after which they are transferred to the ward on the subsequent morning. Inotropic drugs are used restrictively. The definition of postoperative heart failure (PHF) in this study was based on the attending physician's clinical diagnosis of heart failure together with a postoperative stay in the intensive care unit (ICU) exceeding 48 hours and the patient having inotropic support (adrenaline, milrinone, levosimendan or dobutamine), or a need for a circulatory assist device for at least 24 hours after surgery.

During the study period our institution did not have a structured follow-up program for patients and partners after cardiac surgery. All patients fulfilling the criteria above for PHF were invited to participate together with their partners. All of the patients cohabited with a partner who was responsible for the patient during the recovery process at home as well as for household chores. The patient and the partner were required being able to communicate in Swedish, and both were asked to return written informed consent before they were contacted by telephone and verbally informed about the study 2 weeks after discharge.

Procedure

After discharge from hospital, written information about the study was sent to the patients. About two weeks later, the patients were contacted for consent to ask partners about participation. If the patients and partners gave their consent, they were thereafter contacted by telephone and asked about willingness to participate. A time was set for a first individual meeting for those family members who accepted participation. At that meeting, further 
verbal information about the study was given. Before randomization, the participants filled out baseline questionnaires. Dyads that chose to participate were randomized to either the control or experimental group. The randomization was performed using a random-number table with block of 12.

Standard care

The patient-partner dyads in both groups received standard care, as provided by hospital routines in the care of cardiac surgery patients. The patients arrived to the unit one day before surgery and received information from the thoracic surgeon, thoracic anesthetist and a nurse. After 1 month, the same nurse contacted the patients for a follow-up call. The partners were not systematically involved in the pre- and postoperative information.

The intervention

In the intervention group, the patient-partner received conventional care, and in addition psycho educational support from an interdisciplinary team consisting of a physician, nurse and physiotherapist in order to provide patient-partner with the opportunity to process their experiences in the context of cardiac surgery and rehabilitation. Information and advice was also provided to the patient and partner to help them handle the rehabilitation phase. The intervention included 3 support sessions. The first 
was 4-6 weeks after discharge, the second after10-12 weeks, and the third 22-24 weeks after discharge. Each session lasted 30-60 minutes. The first session involved the entire multidisciplinary team and the last two involved telephone consultation by the team nurse. If the patient-partner in addition to the three standard sessions needed additional support, they could be referred to a social worker who was part of the intervention team.

The psychoeducational support highlighted different situations that created stress. Proposed solutions were discussed as well as the dyads' relationship and their mutual needs of support from each other, other family members and from the team.

During the first session, semi-structured dialogues guides, one for each profession, were used. The dialogue guides focused on the patient-partner ' questions and concerns in relation to their situation and their individual goals. During the telephone-call sessions, the nurse used an additional dialogue guide as well as previous notes to be able to reconnect to the earlier dialogues. After each session the nurse summarised the content of the discussions. The dialogue guides were developed by the above mentioned interdisciplinary team based on current literature and the results of a previous study (Agren, Frisman, 2009).

Example from the dialogue guides are given in Table 1.

The patients in the control group received no follow-up visits. 


\section{Data collection}

For this pilot study a battery of questionnaires was used including a demographic questionnaire, Charlson Comorbidity Index, SF-36, Beck Depression Inventory and Perceived Control. Data were collected at baseline at the time of hospital discharge and at 3 and 12 months after discharge. Clinical data were recorded from the medical charts.

\section{Surgical data}

Emergency operation was defined as a procedure usually performed immediately but not later than 24 hours from admittance. Urgent operations were defined as scheduled procedures within one week on patients unable to leave the hospital because of clinical condition.

EuroSCORE (European System for Cardiac Operative Risk Evaluation) was used to calculate the risk of operative mortality as part of clinical routine (Nashef SA, 1999).

Demographic data including health history were collected using a selfadministrated questionnaire identifying age, gender, education, habits such as smoking, alcohol consumption, physical activity, and psychosocial support.

Charlson co-morbidity index scale (CCI) This index is a validated method of classifying co-morbidity. Each condition is assigned a score of 1, 2, 3, or 6 , depending on the risk of dying in connection with the condition. Scores 
are summed to provide a total score to predict mortality. Inter-rater and testretest reliability was good, ranging from 0.74-0.95 (Charlson et al. , 1987). Short Form (SF) - 36: The SF-36 is a multi-purpose, short-form health survey with 36 questions. It yields an 8-scale profile of functional health and well-being scores. The physical part is made up of the dimensions of physical functioning, physical role functioning, bodily pain and general health, and the mental part of the four dimensions of vitality, social functioning, emotional role functioning and mental health. A higher score indicates better health (Ware JE, 1993). SF-36 has been found to have good reliability and validity (Sullivan et al. , 1995, Ware, 2000, Ware and Sherbourne, 1992). The reliability Crohnbach's Alpha values in this study for the different dimensions ranged from 0.83-0.92 for partners and 0.870.88 for patients.

Beck Depression Inventory (BDI-II): is a 21-question multiple-choice selfreport inventory, one of the most widely used instruments for measuring the severity of depression. In its current version the questionnaire is designed for individuals aged 13 and over, and is composed of items relating to symptoms of depression such as hopelessness and irritability, cognitions such as guilt or feelings of being punished, as well as physical symptoms such as fatigue, weight loss, and lack of interest in sex. Each answer is scored on a scale value of 0 to 3 . Higher total scores indicate more severe depressive symptoms. The cut-off score for having symptoms of depression is $>13$; 14-19: mild depression; 20-28: moderate depression; and 29-63: severe depression (Beck AT \& Steer RA, 1971, Beck AT, 1996, Beck AT, 1988). The instrument has been validated in Swedish (Beck AT, 2005). The 
reliability Crohnbach's Alpha values for this study were 0.85 for patients, 0.77 for partners.

Control Attitude Scale (CAS): is a 4-item tool designed to measure the level of perception of control felt by individuals with cardiac disease. The CAS was also used in the partners. (Moser and Dracup, 1995). Response statements are scored on a scale from 1 (none) to 7 (very much). The total score range is 4 to 28 , with higher scores reflecting higher levels of perceived control. (Moser and Dracup, 1995, 2000). The reliability Crohnbach's Alpha was 0.72 for patients, 0.87 for partners in this study. A psychometric testing for the Swedish translation has shown good validity and a reliability coefficient alpha $>0.80$ for the patient version and between 0.60 and 0.70.for the partner version (Årestedt et al. , 2013).

Statistical analysis

Frequencies were run to determine the amount of missing data. Missing data on SF-36 were imputed by the mean of the subscale if only 1 item in a subscale was missing, in BDI-II were imputed by 0 and CAS were not replaced, because there are no recommendations for imputation from the constructors of these instruments.

Patient characteristics and clinical, HRQoL, BDI-II and CAS outcomes were described using means $( \pm \mathrm{SD})$ for continuous variables and using percentages and numbers for categorical variables. For the analysis of characteristics and clinical frequencies, Fisher's exact test was performed in all variables except for Euroscore, age and CCI where we used student ttest. For comparisons between the different groups we used Friedman test, 
the non-parametric alternative to the one-way analysis of variance (ANOVA) with repeated measures in education level, smoking habits, drinking habits, exercise habits, SF-36, CAS, BDI-II and post hoc analyses as Tukey was used to correct for multiple comparisons.

The effects were analysed by mean difference in HRQoL and CAS, all with non-parametric test between baseline, 3 months and 12 months by using Wilcoxon signed-rank test and Fisher's exact test.

The categorisation of co-morbidity BDI-II for the control and experimental groups were compared by Fisher's exact test. The level for statistical significance was set to $p<0.05$. Statistical analysis was performed with the use of SPSS release 20.0 for Windows.

\section{Ethical aspects}

The study was approved by the Regional Ethical Review Board in Linköping (Dnr M178-04) and took place between May 2007 and August 2011. The principles outlined in the Declaration of Helsinki were followed. All patients and partners received verbal and written information about the study. This included the assurance of confidentiality, voluntary participation and the right to withdraw from participation at any time. An informed consent was signed by partners to assure the participants confidentiality. Patient and partners in the control group did not receive follow up since this was not part of standard care. Before this study, there was no evidence that the type of follow up as providing in the intervention since this had not had not been tested. 


\section{Results}

Study participants

A total of 50 dyads fulfilled the inclusion criteria. However 8 declined participation and 42 dyads completed baseline assessment. Due to the block of 12 , the randomization resulted in 17 in the control group and 25 in the intervention group. Thirteen patients were not alive after 12 months, 7 in the control group and 5 in the intervention group. Table 2 describes baseline characteristics of the studied sample. The mean age of partners in the intervention group was 66 and in the control group 67 years. Patients in the intervention group had a mean age of 69 years and 70 years in the control group. Eighty - four percent of the partners were females in the intervention group and compared to $94 \%$ in the control group.

The partners in the intervention group had significantly higher educational level and a higher intake of alcohol (Table 2).

The patients were generally high-risk patients in both groups according to EuroSCORE, with a trend towards higher EuroSCORE in the control group $(9.8 \pm 4.3$ in the control group $v 7.8 \pm 3.2$ in the intervention group; $\mathrm{p}=0.08$ ). Approximately half of the procedures in both groups were done urgently or emergently. In the intervention group coronary artery bypass surgery was done in 18 patients of whom 8 had additional valve procedures: aortic valve + mitral valve $(n=1)$, aortic valve $(n=3)$, mitral valve $(n=3)$ and tricuspid valve $(\mathrm{n}=1)$. Isolated valve procedures were done in 5 patients: aortic valve + mitral valve $(n=1)$, aortic valve $(n=1)$ and mitral valve $(n=3)$. Two patients underwent surgery on the ascending aorta. 
In the control group coronary artery bypass surgery was done in 8 patients of whom one had a repair of post-infarct ventricular septum rupture and 3 had additional valve procedures: aortic valve $(n=1)$ and mitral valve $(n=2)$. Isolated valve procedures were done in 6 patients: aortic + mitral valve $(n=3)$ and aortic valve $(n=3)$. Three patients underwent surgery on the ascending aorta.

Health related quality of life

No significant differences were found between the intervention and control group regarding dimensions of SF-36 after 3 and 12 months. However, there was a significant improvement in SF-36 dimensions over time within the intervention, $\mathrm{p}<0.01$.

Partners to post cardiac surgery heart failure patients increased their health in the dimensions role emotional and mental health and patients increased their health in the dimensions vitality, social function and mental health after a psychoeducational support intervention.

Patients increased their health in the control group at 3 months but not at 12 months, while the intervention group increased their health at both 3 and 12 months. Partners were unchanged over time in control group, but improved in the intervention group at 12 months (figure 2).

Symptoms of depressions

Regarding symptoms of depression there were no significant differences between the groups, neither for patients or partners. Patients in the 
intervention group had less symptoms of depression after 3 months although an increase in symptoms was seen after 12 months (Table 3).

\section{Perceived control}

Patients in the intervention group improved their perceived control significantly $(\mathrm{p}<0.05)$ at 3 months and 12 months compared to baseline (figure 3). Among control patients and in both partner groups no significant changes over time were seen.

\section{Discussion}

In the present study of post cardiac surgery heart failure dyads, psycho educational support from an interdisciplinary team consisting of a physician, nurse and physiotherapist improved health and perceived control significantly after both 3 and 12 months. These results suggest that interventions focusing on psychoeducational support can improve the life situation for the patient-partner and especially for the patients. The effect on the partners was less pronounced. The team approach employed seems to be a promising way of providing follow-up in post cardiac surgery heart failure dyads.

We found that better health and a higher perceived control were associated with psycho educational support in post cardiac surgery HF patients. A 
meta- analysis of psychosocial intervention with family involvement in chronic illness also found that interventions involving the partner had positive effects on patients' health and on decreasing depression and, in some cases, also on decreasing mortality. Among family members, effects were found for decreasing caregiving burden, depression, and anxiety. A meta-analysis showed that family involvement resulted in significantly better health than standard treatment for all outcomes. There was a tendency towards higher effects in relationship-oriented family interventions, compared to educational interventions (Hartmann, Bazner, 2010, Martire LM, 2004).

In our intervention study, we could not see any effect on depression symptoms. Sullivan et al. found that psychoeducational intervention reduced anxiety and depression in a prospective cohort study on patients with $\mathrm{HF}$ (Sullivan, Wood, 2009). In our study there were no differences regarding symptoms of depression between the groups, neither for patients nor partners. The intervention ended after 22-24 weeks and it may be the reason that depression decreased after 3 months but increased after 12 months. A needs-based education intervention in an intensive care unit reduced anxiety and increased satisfaction of family needs (Chien, Chiu, 2006). During the patient's hospitalisation, nurses are in a key position to support family members, maintain family integrity, and prepare them for assuming the role of caretaker during the patient's recovery and management of health at home (Eggenberger SK, 2007, Fry and Warren, 2007, Leon and Knapp, 2008, Van Horn and Kautz, 2007). Follow-up visit was seen as an important way of 
learning what had happened and why during the period of critical illness (Engstrom, Andersson, 2008).

Our findings show increased health and better control, especially for the patients, when patient-partner had postoperative contacts and follow up with healthcare professionals. Fewer opportunities exist to provide necessary information and respond to patient concerns in hospital, and much of the process of wound healing and recovery that previously took place in hospital occurs after discharge(Driscoll et al. , 2009). When the families and the patients are well informed there is a basis for fruitful conversation between them and the healthcare professionals, and everyone can be better prepared if complications occur (Ivarsson B, 2011).

All surgical procedures affect the physical and mental conditions of patientpartner to some degree. This is more evident after life threatening procedures such as cardiac operations. Patients experience emotional problems such as worse physical condition, pain and psychological fear in the preoperative period which could affect them postoperatively. Personality and coping strategies are also factors that play an important role. Patients exhibit problems with attention, memory and concentration in the postoperative period which are probably linked to their emotional state. Emotional problems experienced by the patients may be associated with low self-esteem, the lack of self-confidence and the dependence on others (Boudrez and De Backer, 2001, Merkouris A, 2009). Multidisciplinary follow-up after intensive care can be of value in identifying untreated 
physical and psychological problems in ICU survivors (Schandl et al. , 2011).

Attention should be given to the physical and mental state of the patients before and after the operation, the information and education of the patients and their families. Finally, further research is needed to investigate the patient-partner' needs to meet other persons in the same situation.

The results have to be interpreted cautiously and need be confirmed in larger studies as this is a pilot study, with all its limitations, such as small sample size. This may have contributed to the observed inter-group differences in co-morbidity, university education and drinking habits. Also regarding the difference at baseline in symptoms of depression between the patients in the control group and intervention, the sample may have influenced that the difference between the groups did not reach statistical significance. However, the findings of this pilot study provide information that can serve as basis for future more extensive and systematic studies of these patientpartner also including an evaluation of the costs and benefits of the intervention.

\section{Conclusion}

The results of this study suggest that psychoeducational support from a multidisciplinary team to post cardiac surgery heart failure dyads improves health and perceived control in patients after 3 and 12 months. Partners also seem to improve emotional and mental health. The beneficial effects of the psychoeducational support were more pronounced among patients than partners. Further studies focusing on partners' support are warranted. 


\section{Implications for Clinical Practice}

\section{What's New?}

- Psychoeducational support from an interdisciplinary team consisting of a physician, nurse and physiotherapist to post cardiac surgery heart failure dyads can improve health and perceived control over the heart disease.

- The psychoeducational support seems to be more effective among patients than partners.

\section{Clinical Pearls}

- Interventions focused on psychoeducational support may improve the life situation for the patient-partner and especially for the patients.

- Attention should be given to the physical and mental state of the patients before and after the operation, the information and education of the patients and their families.

\section{Acknowledgments, sources of financial support}

Financial Support was obtained from National Association of Heart and Lung diseases.

We thank the post cardiac surgery heart failure dyads who participated in the study, the secretaries at the department of Cardiothoracic Surgery, Linköping University Hospital especially Maj Britt Tornell for support with 
data collection. Thanks also to Helen Nyberg and Anette Brostedt for support and commitment in connection with the intervention, Mats Fredrikson and Kristofer Årestedt for statistical advice.

\section{Author contributions}

$\mathrm{S} \AA$, AS, RS and SB were responsible for the study conception and design and $\mathrm{S} \AA$ and $\mathrm{AS}$ were responsible for the drafting of the manuscript. $\mathrm{S} \AA$ performed the data collection and $\mathrm{S} \AA, \mathrm{AS}, \mathrm{SB}$ and RS performed all the data analysis. SÅ obtained funding. SA, AS, RS and SB made critical revisions to the paper and final approval of the version to be submitted.

\section{Conflict of interest statement}

The authors declare no potential conflicts of interest with respect to the research, authorship, and/or publication of this article.

The authors disclose receipt of the following financial support for the research, authorship, and/or publication of this article: Linköping University, National Association of Heart and Lung diseases and the Swedish Institute for Health Sciences. 


\section{References}

Agren S, Frisman GH, Berg S, Svedjeholm R, Stromberg A. Addressing spouses' unique needs after cardiac surgery when recovery is complicated by heart failure. Heart Lung. 2009;38:284-91.

Beck AT \& Steer RA. Beck Depression Inventory., Revised Edition (BDI). (Research Instrument). 3:e ref ed. 555 Academic Court, San Anonio, TX 78204: The psychlogical corporation; 1971.

Beck AT BGSR. Beck Depression Inventory II Manual. 555 Academic Court, San Antonio, TX 78204.: The Psychological Corporation; 1996.

Beck AT SR, Brown GK. . Manual for the Beck depression Inventory-II (svensk version). Sandviken.: Psykologiförlaget.; 2005.

Beck AT SRGM. Psychometric properties of the Beck Depression Inventory: Twenty-five years of evaluation. Clinical Psychology Review. 1988;8:77-100.

Boudrez H, De Backer G. Psychological status and the role of coping style after coronary artery bypass graft surgery. Results of a prospective study. Qual Life Res. 2001;10:37-47.

Boyd KJ MS, Kendall M, Worth A, Frederick Benton T, Clausen H. Living with advanced heart failure: a prospective, community based study of patients and their carers. Eur J Heart Fail. 2004;6:585-91.

Boyd KJ, Worth A, Kendall M, Pratt R, Hockley J, Denvir M, et al. Making sure services deliver for people with advanced heart failure: a longitudinal qualitative study of patients, family carers, and health professionals. Palliat Med. 2009;23:767-76.

Charlson ME, Pompei P, Ales KL, MacKenzie CR. A new method of classifying prognostic comorbidity in longitudinal studies: development and validation. J Chronic Dis. 1987;40:373-83.

Chelsa A. Do Family Interventions Improve Health? . Journal of Family Nursing. 2010;16:355-77.

Chien WT, Chiu YL, Lam LW, Ip WY. Effects of a needs-based education programme for family carers with a relative in an intensive care unit: a quasi-experimental study. Int J Nurs Stud. 2006;43:39-50. Doering LV MD, Lemankiewicz W, Luper C, Khan S. Depression, healing, and recovery from coronary artery bypass surgery. Am J Crit Care 2005;14:Am J Crit Care. 2005 Jul;14(4):316-24.

Driscoll A, Davidson P, Clark R, Huang N, Aho Z. Tailoring consumer resources to enhance self-care in chronic heart failure. Aust Crit Care. 2009;22:133-40.

Eggenberger SK NT. Being family: the family experience when an adult member is hospitalized with a critical illness. J Clin Nurs. 2007;16:1618-28.

Engstrom A, Andersson S, Soderberg S. Re-visiting the ICU Experiences of follow-up visits to an ICU after discharge: a qualitative study. Intensive Crit Care Nurs. 2008;24:233-41.

Fry S, Warren NA. Perceived needs of critical care family members: a phenomenological discourse.

Crit Care Nurs Q. 2007;30:181-8.

Hartmann M, Bazner E, Wild B, Eisler I, Herzog W. Effects of interventions involving the family in the treatment of adult patients with chronic physical diseases: a meta-analysis. Psychother Psychosom. 2010;79:136-48.

Holm J HR, Vánky F, Svedjeholm R. Mixed venous oxygen saturation is a prognostic marker after surgery for aortic stenosis. Acta Anaesthesiol Scand 2010;54:589-95.

Ivarsson B LS, Lührs C, Sjöberg T. Serious complications in connection with cardiac surgery--next of kin's views on information and support. Intensive Crit Care Nurs. 2011;27:331-7.

Knoll SM JJ. Uncertainty and expectations: taking care of a cardiac surgery patient at home. J

Cardiovasc Nurs. 2000;14:64-75.

Leon AM, Knapp S. Involving family systems in critical care nursing: challenges and opportunities. Dimens Crit Care Nurs. 2008;27:255-62.

Lopez V SYCPC, Wai Y. Physical, psychological and social recovery patterns after coronary artery bypass graft surgery: a prospective repeated measures questionnaire survey. Int J Nurs Stud. 2007;44:1304-15.

Martire LM LA, Schulz R, Miller GE, Helgeson VS. Is it beneficial to involve a family member? A metaanalysis of psychosocial interventions for chronic illness. Health Psychol 2004;23:599-611. 
McCrone S, Lenz E, Tarzian A, Perkins S. Anxiety and depression: incidence and patterns in patients after coronary artery bypass graft surgery. Appl Nurs Res. 2001;14:155-64.

Merkouris A AE, Pistolas D, Papagiannaki V, Diakomopoulou E, Patiraki E. Quality of life after coronary artery bypass graft surgery in the elderly. Eur J Cardiovasc Nurs. 2009;8:74-81. .

Micik S, Borbasi S. Effect of support programme to reduce stress in spouses whose partners 'fall off' clinical pathways post cardiac surgery. Aust Crit Care. 2002;15:33-40.

Moser DK, Dracup K. Psychosocial recovery from a cardiac event: the influence of perceived control. Heart Lung. 1995;24:273-80.

Moser DK, Dracup K. Impact of cardiopulmonary resuscitation training on perceived control in spouses of recovering cardiac patients. Res Nurs Health. 2000;23:270-8.

Mårtensson J DK, Fridlund B. Decisive situations influencing spouses' support of patients with heart failure: a critical incident technique analysis. Heart Lung 2001;30:341-50.

Nashef SA RF, Michel P, Gauducheau E, Lemeshow S, Salamon R. European system for cardiac operative risk evaluation (EuroSCORE). Eur J

Cardiothorac Surg. 1999;16:9-13.

Schandl AR, Brattstrom OR, Svensson-Raskh A, Hellgren EM, Falkenhav MD, Sackey PV. Screening and treatment of problems after intensive care: a descriptive study of multidisciplinary follow-up.

Intensive Crit Care Nurs. 2011;27:94-101.

Sharif F NK, Ashkani H, Zoladl M. The effect of psycho-educational intervention on the life quality of major depressive patients referred to hospitals affiliated to Shiraz University of Medical Sciences in Shiraz-Iran. Iran J Nurs Midwifery Res 2012;17:425-9.

Sullivan M, Karlsson J, Ware JE, Jr. The Swedish SF-36 Health Survey--I. Evaluation of data quality, scaling assumptions, reliability and construct validity across general populations in Sweden. Soc Sci Med. 1995;41:1349-58.

Sullivan MJ, Wood L, Terry J, Brantley J, Charles A, McGee V, et al. The Support, Education, and Research in Chronic Heart Failure Study (SEARCH): a mindfulness-based psychoeducational intervention improves depression and clinical symptoms in patients with chronic heart failure. Am Heart J. 2009;157:84-90.

Tully PJ, Baker RA, Turnbull D, Winefield $\mathrm{H}$. The role of depression and anxiety symptoms in hospital readmissions after cardiac surgery. J Behav Med. 2008;31:281-90.

Tully PJ, Baker RA, Turnbull DA, Winefield HR, Knight JL. Negative emotions and quality of life six months after cardiac surgery: the dominant role of depression not anxiety symptoms. J Behav Med. 2009;32:510-22.

Van Horn E, Tesh A. The effect of critical care hospitalization on family members: stress and responses. Dimens Crit Care Nurs. 2000;19:40-9.

Van Horn ER, Kautz D. Promotion of family integrity in the acute care setting: a review of the literature. Dimens Crit Care Nurs. 2007;26:101-7; quiz 8-9.

Vanky FB, Hakanson E, Svedjeholm R. Long-term consequences of postoperative heart failure after surgery for aortic stenosis compared with coronary surgery. Ann Thorac Surg. 2007;83:2036-43.

Vanky FB, Hakanson E, Tamas E, Svedjeholm R. Risk factors for postoperative heart failure in patients operated on for aortic stenosis. Ann Thorac Surg. 2006;81:1297-304.

Ware JE. SF-36 health survey manual and interpretation guide. Boston.: The New Health Institute, New England Medical Center.; 1993.

Ware JE, Jr. SF-36 health survey update. Spine (Phila Pa 1976). 2000;25:3130-9.

Ware JE, Jr., Sherbourne CD. The MOS 36-item short-form health survey (SF-36). I. Conceptual framework and item selection. Med Care. 1992;30:473-83.

Årestedt K, Ågren S, Flemme I, Moser DK, Strömberg A. A psychometric evaluation of the 4-item version of the Control Attitudes Scale for patients with cardiac disease and their partners.

Unpublished. 2013. 


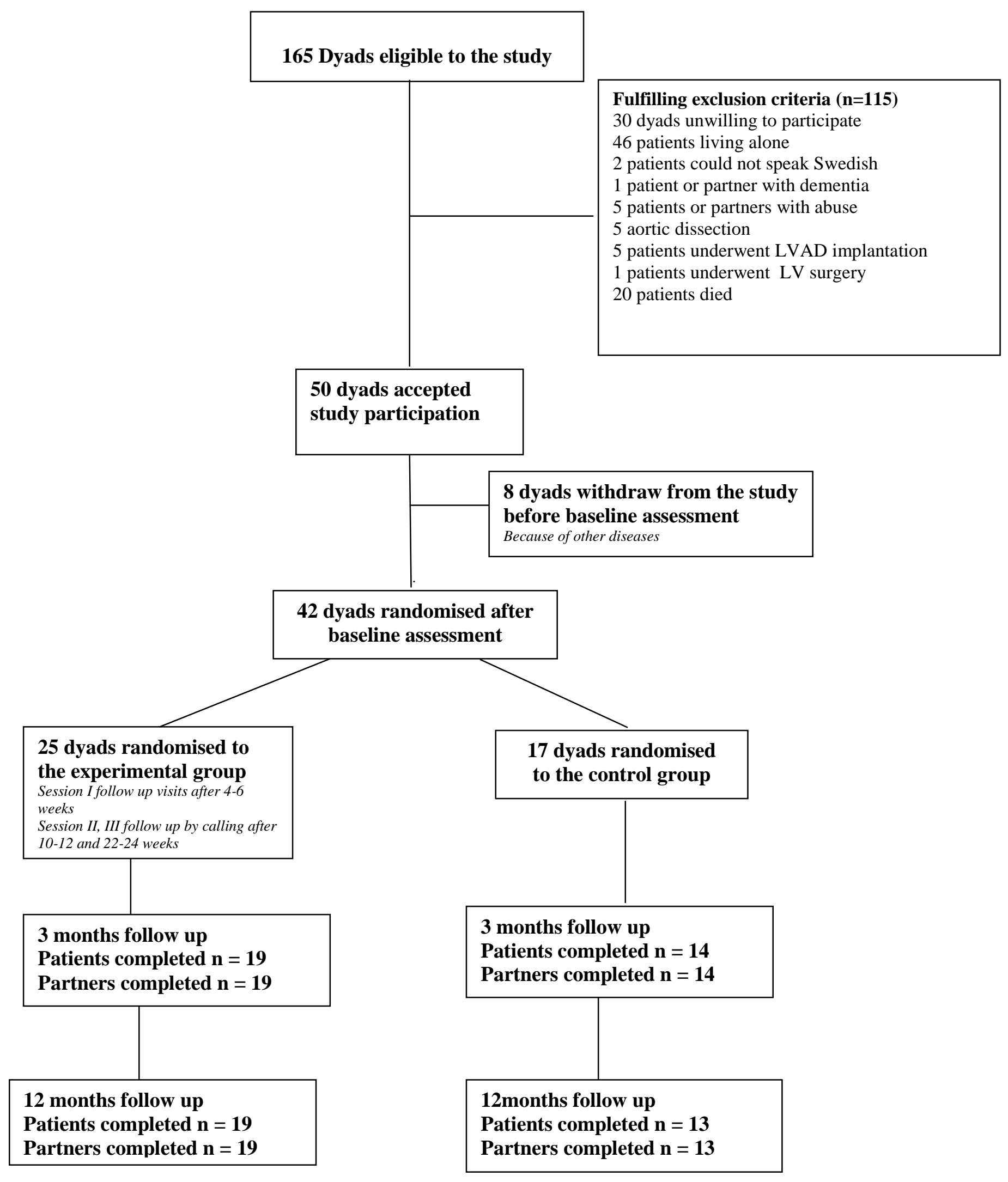

Figure 1. Flow chart illustrating the dyads through the clinical study.

LVAD = Left ventricular assist device; $L V=$ Left ventricle. 

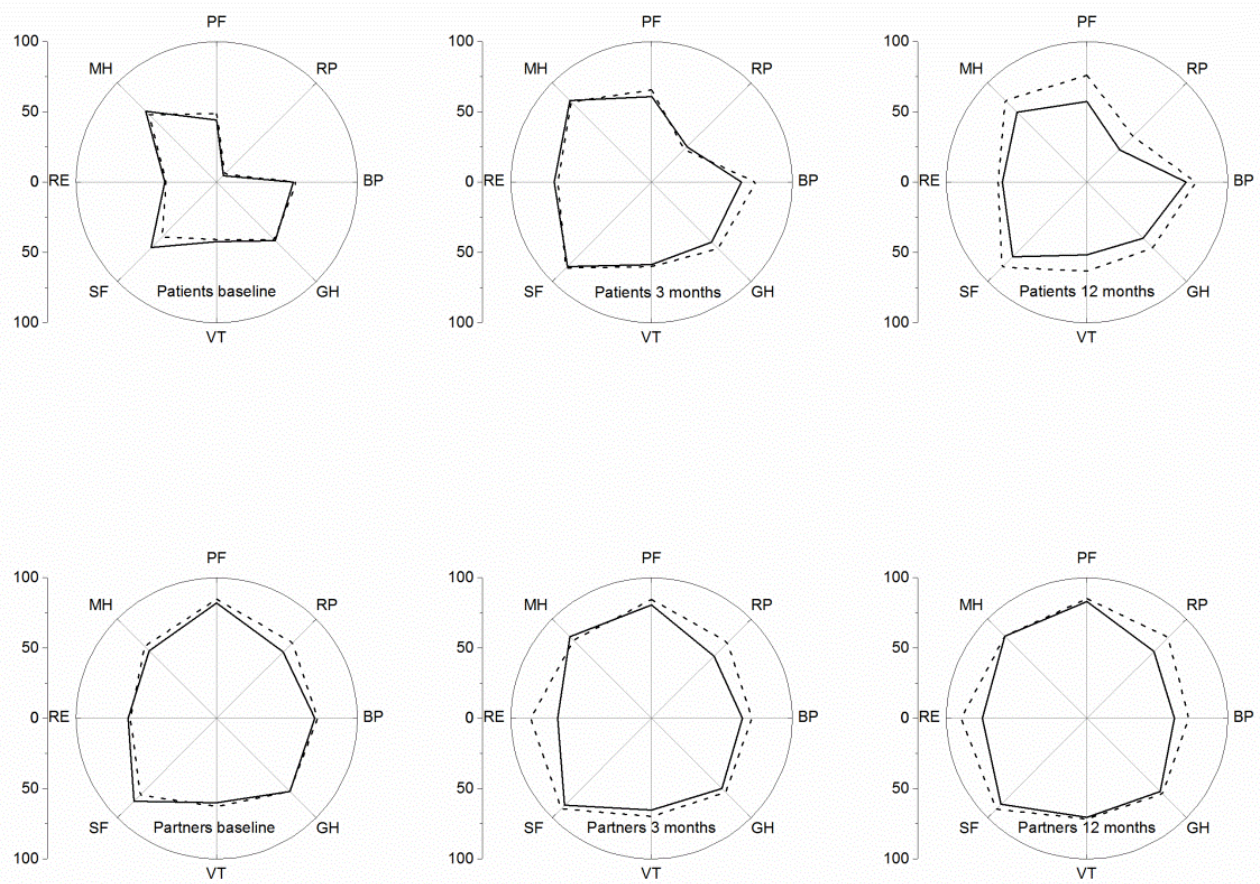

Patients (top row) and partners (bottom row) at baseline, 3 months and 12 months

Figure 2 Graphs illustrating the SF-36 of the dyads. 

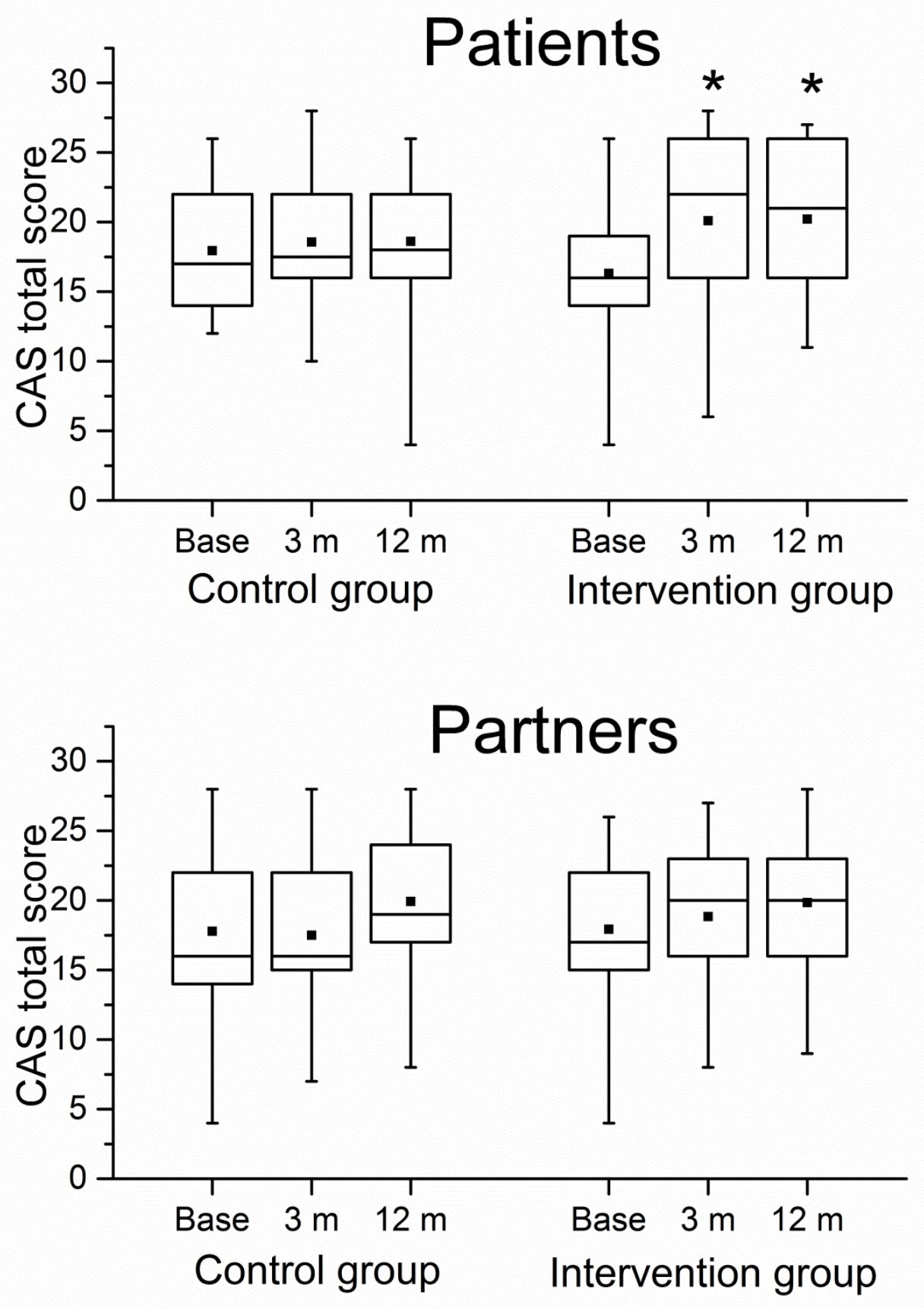

Figure 3. Box plot of CAS (control attitude scale) at baseline, 3 months and 12 months for patients (top) and partners (bottom). Patients in the intervention group show higher scores at 3 and 12 months compared to baseline. Box indicates $25 \%-75 \%$ percentiles, line is median and dot is mean, whiskers are range, $*=p<0.05$. 
Table 1

Example from the dialogue guides

- Outline objectives of the visit

- Adress questions from both patient and partner about the situation in the hospital or at home

- Goals of improvement for both the patient and partner to improve their situation

- Further needs of education and support today and in the future

Table 2

Clinical and demographic characteristics of the patients and partners

$\begin{array}{llllll}\text { Patient } & \text { Patient } & \text { p- } & \text { Partner } & \text { Partner } & \text { p-value } \\ \text { control } & \text { intervention } & \text { value } & \text { control } & \text { intervention } & \\ (n=17) & (n=25) & & (n=17) & (n=25) & \end{array}$

\section{Gender}

Male

$16(94 \%) \quad 21(84 \%)$

ns

$1(6 \%)$

$4(16 \%)$

ns

Age

$69(8.4)$

$70(9.1)$

ns

$66(7.9)$

67 (6.6)

ns

Urgent-

$8(47 \%)$

$13(52 \%)$

ns

emergent

procedure

$\begin{array}{llll}\text { EuroSCORE } & 9.8(4.3) & 7.8(3.2) & 0.08\end{array}$

\section{Education}

level

ns

Primary

$6(35 \%)$

$2(8 \%)$

$5(29 \%)$

$3(12 \%)$

school

Elementary

$8(47 \%)$

$11(44 \%)$

$9(53 \%) \quad 6(24 \%)$

school

Upper

$1(6 \%)$

$6(24 \%)$

$2(12 \%) \quad 8(32 \%)$ 
secondary

school

$\begin{array}{llll}\text { University } & 2(12 \%) & 6(24 \%)) & 1(6 \%)\end{array}$

\section{Drinking}

habits

ns

0.01

Never

$3(17 \%) \quad 2(8 \%)$

$5(29 \%) \quad 2(8 \%)$

1 glass/week

$8(48 \%)$

$7(28 \%)$

$11(65 \%) \quad 6(24 \%)$

$2-7$

$5(29 \%)$

$13(52 \%)$

$1(6 \%) \quad 17(68 \%)$

glasses/week

$>7$

$1(6 \%) \quad 3(12 \%)$

0

0

glasses/week

Smoking

ns

ns

habits

Smoke

0

$1(4 \%)$

$3(17 \%) \quad 6(24 \%)$

regularly

Previous

$9(53 \%)$

$13(52 \%)$

$3(17 \%) \quad 8(32 \%)$

Never

$8(47 \%)$

$11(44 \%)$

$11(66 \%) \quad 11(44 \%)$

Exercise

ns ns

\section{habits}

$\begin{array}{lllll}<30 \min & 3(17 \%) & 5(20 \%) & 0 & 1(4 \%) \\ 30-60 \min & 6(35 \%) & 3(12 \%) & 4(24 \%) & 5(20 \%) \\ 1-3 & 4(24 \%) & 13(52 \%) & 3(17 \%) & 9(36 \%)\end{array}$


hours/week
$\geq 3$
$4(24 \%)$
$4(16 \%)$
$10(59 \%) \quad 10(40 \%)$

hours/week

CCI

$4.5(2.4)$

$5.0(2.4)$

ns

$1.8(1.9)$

$1.9(2.7)$

ns

\section{Table 3}

Distribution of the categorisation of Beck Depression Inventory II for patients and partners in the control and experimental groups at baseline, after 3 and 12 months. No significant differences were found between the groups.

\begin{tabular}{|l|l|l|l|l|}
\hline Depressive symptoms according to & Patient & Patient & Partner & Partner \\
BDI-II (score 14-63) & control & intervention & control & intervention \\
\hline Baseline & & & & \\
3 months & $2(11 \%)$ & $8(32 \%)$ & $3(16 \%)$ & $2(8 \%)$ \\
12 months & $3(16 \%)$ & $3(12 \%)$ & $2(11 \%)$ & $2(8 \%)$ \\
& $4(36 \%)$ & $5(28 \%)$ & 0 & $3(16 \%)$ \\
\hline
\end{tabular}

